\title{
Having a life versus being alive
}

\author{
Thomasine Kushner Department of Psychiatry, University of Miami School of Medicine
}

\section{Author's abstract}

In an attempt to provide some clarification in the abortion issue it has recently been proposed that since 'brain death' is used to define the end of life, 'brain life' would be a logical demarcation for life's beginning. This paper argues in support of this position, not on empirical grounds, but because of what it reflects of what is valuable about the term 'life'. It is pointed out that 'life' is an ambiguous concept as it is used in English, obscuring the differences between being alive and having a life, a crucial distinction for bioethical questions. The implications of this distinction for the moral debate about abortion are discussed.

The United States Supreme Court, by recently striking down most laws aimed at discouraging abortions, has reaffirmed its bitterly controversial ruling of a decade ago. Although the ruling has been hailed by 'prochoice' forces and lamented by 'right-to-life' advocates both supporters and opponents agree that the question whether a woman has a right to an abortion has now shifted to the political arena where it promises to be a major debate topic in the Senate and the 1984 election campaign.

Until now President Reagan has limited his remarks on the issue to code words fit for slogans, occasional paragraphs in speeches or abbreviated press conference replies. This has changed and, expressing his 'profound disappointment' regarding the Supreme Court's decision, Reagan has launched an effort to rally the country against abortion by writing an article which was published not long ago (1). In it the President argues that abortion is not merely a personal decision since 'We are talking about two lives - the life of the mother and the life of the unborn child'. Reagan is also using the media to lobby vigorously by promising to 'fight as long and hard as I can' to curb abortion, warning that 'we must never become a society in which an individual has the right to do away with inconvenient life' (2).

Mr Reagan's view illustrates how the abortion question is inextricably linked with the notion of 'life'

\section{Key words}

Abortion; brain death; 'life'; medical ethics.
- a concept whose meaning is far from clear.

In an attempt to arrive at some understanding regarding the term, members of congress in the senate hearings on 'human life' interviewed physicianor hoping that those persons professionally dedicated tQ the protection and preservation of life could provide some insights which would help to define the term? Those doctors interviewed, however, denied an special knowledge and declared themselves unable to provide any expert testimony on the question of 'life's and when it could be said to begin.

In the New England Fournal of Medicine, Dr John M Goldenring challenges the professed inability of the physicians to offer judgments in this area, since as he points out, doctors are commonly called upon to mak the decision whether a person is alive or dead. He also calls attention to the fact that the criteria used for this pronouncement have changed. While at one time the status of the cardio-respiratory system was used as at sufficient determinant, technology now makes possible to replace those functions, thus prompting physicians to look for a different measurement. Tha measurement, as $\mathrm{Dr}$ Goldenring explains, is 'th function of the only truly unique and irreplaceable organ - the brain' (3).

The implication for Dr Goldenring is that just as 'brain death', the permanent cessation of brairo activity, has been accepted as a reasonable point at which to fix the time of death (4), logic would suggese that 'brain life', the emergence of a functioning brain be adopted as a reasonable time to demarcate the beginning of life. It is Dr Goldenring's view that since् this condition is present in the fetus at about eight weeks of gestation this is the point at which the fetus should be considered, in his words, 'a living humaßs being' (3).

The question needs to be raised as to whether 'braif? life' is a good criterion for life from a medical and morato perspective. I would argue that it is, but the reason wh might be easily misunderstood. The misunderstanding arises from assuming the problem of determining the beginning of life to be just a technical difficulty solvedf by medical experts solely on the basis of physiologicar processes. On the contrary, fixing the beginning of life is a problem requiring the consideration of othes. factors in addition to empirical facts. 
No exact point can be indicated as the boundary marker for life. Instead, what is involved is a sequence of developing processes from conception, differentiation, heart beat, beginning of brain function, etc. This means that the physiological facts, instead of allowing us to establish a particular point as the juncture at which life begins, allow us only to set perimeters, or limits around a general range of functions.

Taking this into consideration, this paper will argue that the initiation of brain activity is the most reasonable time at which to fix the start of life, not because there is some empirical argument that establishes it as such, but because (a) it is among the options that are available and (b) because of the connection of brain activity with the possibility of consciousness and the connection of this with what we take to be valuable about the notion of 'life'.

When attempting to ferret out what constitutes life's value, it becomes apparent that unfortunately as the word is used in English it is crucially ambiguous. 'Life' may refer to something that is alive in the sense that inanimate objects, such as trees, are alive, or it might describe a person's biographical existence. In some languages this most important distinction is clearly marked. Greek, for example, has two terms for 'life,' $z o e$ and bios (which form the roots for our words, 'zoology' and 'biography'). As will become apparent, the differences between these two concepts have far reaching implications for bioethics.

Zoe means being alive in a biological sense, and to determine whether or not something is alive in terms of $z o e$ all we need to appeal to are biological criteria. Being alive, zoologically speaking, concerns whether or not the entity in question has a certain sort of organic structure and the state of that organism, ie whether it is functioning in the ways described by biology.

Persons, however, in addition to being functioning organic structures, possess bios in that they have lives. Investigation of this involves more than simply asking biological questions about the function of an organism and its structure. Having a life in this sense means being the subject of a certain life with its accompanying history, nexus of personal and social relationships, complex patterns of psychological characteristics, plus the whole fabric of events as they happen to and affect the individual. Subjects of lives, in this sense, are capable of some degree of problem-solving, effecting relationships that give satisfaction, benefiting from past experiences to influence present situations as well as being capable of experiencing and expressing a range of emotions. While these psychological characteristics are seen as a positive good, it is difficult to say with confidence why this is so. We might say, with a degree of circularity, that these things make life more enjoyable and make it possible to participate in projects we consider important.

If respect for life is to differentiate between the moral value of life in general (including plant and insect life) and the moral value of the lives of persons, then one must interpret the moral rule protecting life as having at its point the protection of the lives and those who are the subjects of lives; the protection of bios rather than mere zoe.

Conversely if it is bios which is truly important morally then the normal species-centered moral approach which cuts a wide swath between humans and all other creatures is only a prejudice since there seems to be no reason to believe that the attributes of bios need be limited to a certain body type or linked to any particular physical characteristics. Instead, the capabilities of bios are a function of structure in that they are predicated on a level of mental development that in turn is evidence of an intact nervous system of a certain complexity. For this reason, those characteristics necessary for having lives (bios) are shared by some higher order animals who do lead rudimentary types of lives, as opposed to just being alive (zoe); these capacities become less pronounced however, as one descends the phylogenetic scale.

The distinction between bios and zoe, having a life and being alive, when applied to the abortion issue makes possible some distinctions perhaps previously overlooked. A problem arises, for example, in the position outlined by Dr Goldenring. He argues that the eight-week fetus with a functioning brain has, as a result, become 'a living human being' the status of which, according to Goldenring, entitles the fetus to the same protection accorded to any person (3). However, while drawing attention to an important biological fact, the wrong conclusion is reached. Dr Goldenring does a service in bringing attention to the fact that brain development has important ethical implications but the significance of this observation is not that the fetus, at this juncture, assumes 'the medical definition of human life' (3). It is that only a functioning brain makes the consciousness possible on which bios depends. It is not 'human life' per se that matters morally, for as indicated above our obligations are not to protect living things but rather to protect things that have lives. From the moment of conception the embryo is alive (zoe) as well as irrefutably human; but the status of a living human being, at any stage, is not the same as that of being the subject of a life in the sense of bios. The morally significant question becomes 'Is the fetus the subject of a life?'.

It is clear that until it has developed a brain capable of consciousness the fetus's biography is not yet started. There is no life (bios) of which the fetus is the subject, although there are lives of which the fetus is a part. The fact that the mother is pregnant may be a very important part of her life and the plans that are being made for the new baby may be a very important part of the family. But even taking into consideration the role the fetus may be playing in the lives of others, the fetus is not yet the subject of biography or the subject of a life. The reason for this is that without a functioning brain the fetus cannot have any of the psychological attributes necessary to make it a human being who is the subject of a life. 
Only gradually in fetal and then infant development does he or she acquire the characteristics of personhood. The process of becoming a person is a lengthy one and even at birth the infant has only some of the necessary psychological attributes such as desires, wants, frustrations and feelings. It will take time for the more complex sets of capacities referred to earlier to develop in the course of interaction between the infant and his environment.

However, the important point is that until the infant has developed a brain capable of consciousness it is impossible for such personal development to occur. Conversely, once a human fetus has developed a brain capable of consciousness its biography - its life in the sense of bios - has begun. Thenceforth it has the capacity to be a person and its moral importance rests on that fact.

Without that capability of consciousness a human being even if alive (zoe) is precluded from being the subject of a life (bios) and therefore from becoming a person. An example of this is the anencephalic, who is alive in the sense of zoe but will never be a subject of a life in the sense of bios. Its absence of capacity for a mental life makes the development of the psychological attributes of a biographical existence impossible.

A normal fetus however, once it has developed a brain capable of consciousness, has become a subject of a developing life (bios) and evolving personhood.

Taking these things into account, it would be possible to establish a moral and indeed legal code recommending that fetuses, once they have developed brains capable of consciousness, should be treated in a special way. Such a code would include the following assumptions:

(i) that abortions prior to the development of a brain capable of consciousness are not morally objectionable; (ii) that if there is going to be an abortion after this stage it should be performed as early as possible, not just for reasons of medical prudence but also from a moral perspective, and

(iii) that people will need reasons of increasing moral strength to justify abortion as the fetus develops. The further the pregnancy continues the stronger the reason would have to be to terminate it.

This position offers a way of addressing some related issues; for example, the controversy within the British medical community concerning experimentation on embryos. Dr Robert Edwards's interest in 'spare embryos' (5) created in a culture dish and not destined for implantation resulted in a furore. Edwards reportedly countered charges of 'Nazi techniques' and the accusation of former British Medical Association officer, Dr Walter Hedgecock, that 'It is really like pinning a baby down on a board and doing experiments on it' by saying 'We must obviously respect embryonic life, but let us be clear that we are talking about microscopic round balls of cells without eyes, ears or organs.'
If accurately reported Dr Edwards's defence reflects the same erroneous assumption expressed by Hedgecock and frequently espoused by antiê? abortionists which equates the presence of a body, with fingers, toes, etc, with being a person. Persons are nof? persons because they have a certain type of body. The justification for experimentation on embryos lies not ir. the absence of identifiable physical characteristics no: in the absence of personhood but in the absence of bios $\stackrel{\varnothing}{\Omega}$ as manifested by the absence of a brain capable of consciousness.

It is important to point out that the view presented here is not so 'liberal' as it might first appear. Thछ weight of Dr Goldenring's observation that brair? functioning is measurable at approximately the eighth week of gestation means that very early on there is. already a complex being with a developing capacity for bios. Therefore, from that early stage in the nine monther process there would have to be a morally substantia? reason for interfering with the fetus's development. -

At first it would appear that if this way of viewing our responsibilities were adopted amniocentesis, 趈 procedure not performed before the fifteenth week and whose results may not be known for several weekso more should be precluded. However, it does not follow甲 from the above analysis that amniocentesis would be entirely useless, all termination at this stage being excluded as a possibility. What does follow is thae strong moral reasons would have to be given for endingo a pregnancy at this time. An example of such a reasono might be that the baby is diagnosed as having a severe birth defect. However, mere desire for a child of the opposite sex could not serve as a justification, since in 3 a moral hierarchy of reasons such a reason would be deemed if not whimsical, at least insubstantial. Even if the response were to be that the parents wanted a childB of the opposite sex very badly, when compared with of severe health defect in the fetus the reason remains frivolous.

This view suggests that before the development of fetal brain capable of consciousness the fetus has noo intrinsic entitlement to protection of its life, which? until then is mere zoe. Nonetheless the fetus is, of course, protected insofar as its mother wishes to
protect it.

Once it has developed a brain capable of consciousness it acquires an intrinsic entitlement to protection by virtue of becoming a subject of life (bios) $\sigma$ From then on its gradual development into a person should be reflected in progressively weightier mora and legal demands for justifications for aborting it.

\section{Acknowledgement}

The author wishes to acknowledge her indebtedness to̊ James Rachels whose influence is pervasive not only in this paper but in her approach to bioethics. 


\section{References}

(1) Reagan R. Abortion and the conscience of the nation. Human life review; spring 1983: 7-16.

(2) Reagan R. From a media interview on September 81982 and quoted in The Miami Herald, 1982 September 12 by James Morin, page 2E.
(3) Goldenring J M. Letter. New England journal of medicine 1982; 307: 564 .

(4) A definition of irreversible coma: report of the Ad hoc Committee of Harvard Medical School to Examine the Definition of Brain Death. Fournal of the American Medical Association 1968; 205: 337-340.

(5) The Miami Herald 1982 Sept 28: 3A.

\section{Obituary}

\section{Lord Amulree, first President of the Society for the Study of Medical Ethics}

Lord Amulree, who was the first President of the Society for the Study of Medical Ethics, died on the 15th of December 1983 at the age of 83. As a consultant physician at University College Hospital, London he had played a leading role in the development of geriatric medicine.

Basil William Sholto Mackenzie was born on 25th July 1900 and was educated at Lancing, Gonville and Caius College, Cambridge and at University College Hospital, London, where he qualified in 1925 . He joined the Ministry of Health in 1936 and returned to clinical medicine in 1949 when he was appointed physician in charge of the newly formed geriatric department at $\mathrm{UCH}$, remaining there until his retirement in 1966.

Lord Amulree was a liberal by nature, with a wide social concern which found expression in his membership of the Liberal Party for which he was chief whip in the House of Lords for 22 years, until 1977 . He succeeded to his father's title in 1942 and was appointed KBE in 1977.

Lord Amulree became the first President of the Society for the Study of Medical Ethics in 1974, an office he still held at the time of his death. The society was founded in 1972, as a development of the London Medical Group (LMG), a student organisation set up in 1963 to sponsor, in the twelve London teaching hospitals, the study of issues raised by the practice of medicine which concern other disciplines. Lord Amulree was Chairman of the Governing Body from 1967 to 1982.

He was committed not only to multidisciplinary studies, but also to the greatest possible role for students in the development of the study of medical ethics. It is not surprising therefore that when he was approached in 1963 to be president of the London Medical Group, he refused, suggesting that a student president might carry more weight. As a result a medical student became the first president of the LMG. Lord Amulree was a notable figure at LMG annual conferences for almost 20 years. His enthusiasm for the medical groups never declined; he perceived them to be by far the most important part of the society's work, as some of his speeches in the House of Lords testify.

He gave constant support to the Director, not only by ensuring the involvement of a wide cross-section of doctors, members of other disciplines and of students, but also in the constant search for funds. Indeed it was a letter signed by Lord Amulree (Pain-killing is not euthanasia, The Times 3 Feb 1973) which attracted the attention of Mr Ernest Kleinwort and Sir Cyril Kleinwort, the merchant bankers, and made possible the publication of the fournal of Medical Ethics.

Not the least of his contributions was his insistence on a fixed time for the ending of all meetings, a characteristic now firmly associated with the London Medical Group.

It is doubtful whether the development of the study of medical ethics in the UK would have taken its present course had it not been for the interest and guidance of Sholto Amulree. 